\title{
LARYNGOMALACIA IN INFANTS
}

\author{
Cristina M. GOANȚĀ ${ }^{1,2}$, Mihail TUȘALIU1,3凶, Lavinia G. SAVA ${ }^{3}$, Vlad A. BUDU ${ }^{1,3}$ \\ ${ }^{1}$ „Carol Davila“ University of Medicine and Pharmacy, Bucharest, Romania \\ ${ }^{2}$ Clinical Emergency Hospital `Sf. Pantelimon“, Bucharest, Romania \\ ${ }^{3}$ Institute of Phonoaudiology and Functional ENT Surgery `Prof. Dr. D. Hociotă“, Bucharest, Romania \\ Received 24 June 2018, Accepted 13 Aug 2018 \\ https://doi.org/10.31688/ABMU.2018.53.3.24
}

\begin{abstract}
Laryngomalacia is a disease that is the most common etiology causing stridor in infants and in most cases the patient presents with inspiratory stridor that worsens during feeding, crying, supine position or agitation. In laryngomalacia the supraglottic structures collapse into the airway during inspiration causing airway obstruction. Typical symptoms are not present at birth, but appear within the first 4 months of life and disappear at maximum 24 months of age. The most common associated symptoms are swallowing dysfunctions, regurgitation, cough and sleep apnea. Laryngomalacia is a self-limiting disease with about $20 \%$ of the patients presenting with severe disease and they require surgical treatment.
\end{abstract}

Keywords: neonatal stridor, laryngomalacia, larynx, glottis.

\section{RÉsumé}

La laryngomalacie du nourrisson

La laryngomalacie est une maladie qui est la cause la plus fréquente d'étiologie chez le nourrisson et dans la plupart des cas, le patient se présente avec un stridor inspiratoire qui s'agrave pendant l'alimentation, les pleurs, la position couchée ou l'agitation. En laryngomalacie, les structures supraglottiques s'effondrent dans les voies respiratoires lors de l'inspiration, provoquant une obstruction des voies respiratoires. Généralement, les symptômes ne sont pas présents à la naissance mais apparaissent dans les 4 premiers mois de la vie et disparaissent à l'âge de 24 mois au maximum. Les symptômes associés les plus courants sont les troubles de la déglutition, la régurgitation, la toux et l'apnée du sommeil. La laryngomalacie est une maladie spontanément résolue, environ $20 \%$ des patients présentant une maladie grave et nécessitant un traitement chirurgical.

Mots-clés: stridor néonatal, laryngomalacie, larynx, glotte. 


\section{INTRODUCTION}

Laryngomalacia is an anomaly of the larynx that affects $50 \%$ to $70 \%$ of infants addressed to the primary care accusing stridor, being the most common congenital anomaly of the laryn $x^{1}$. Noisy breathing is a common presenting symptom among newborns and children and laryngomalacia is the most common cause of stridor in infants ${ }^{1}$.

Parents that present to the doctor are worried because the infant has inspiratory stridor during the first few weeks of life. The stridor is usually getting worse over the first 6 months of age, followed by a gradual improvement and the symptoms usually disappear by 24 months of age ${ }^{2}$.

Symptoms of laryngomalacia include:

- Inspiratory stridor -it is present from birth and is getting worse over the first 6 months of life. After that, as the respiratory system starts to mature, the stridor gets better and by month 24 of life the patients are symptom-free ${ }^{3}$.

- Stridor, that is worse with agitation, crying, feeding or supine position - parents complain about the stridor getting worse during the day, each time the up-named activities occur. After the activity is over, the stridor also goes better or even disappears.

- Difficulty feeding - the patients that have laryngomalacia can also develop dysphagia, aspiration, apnea, reflux or obstructive sleep apnea. In patients with severe disease, pulmonary hypertension may also occur.

Many patients with laryngomalacia also associate gastroesophageal reflux disease (GERD), that needs treatment and also is getting better as the newborn starts to age ${ }^{4}$. When infants swallow, they interrupt breathing and so their compromised airways may not coordinate well sucking, swallowing and breathing, leading to dysphagia and aspiration that may scare the parent.

The etiology of laryngomalacia is considered to be multifactorial. The first one cited are anatomic factors, like abnormal prolapse of laryngeal tissue, associated or not with tissue redundancy, that can lead to supraglottic obstruction and laryngomalacia ${ }^{5}$. Another theory, that is called the cartilaginous theory, suggests that the immaturity of the laryngeal cartilage contributes to the obstruction ${ }^{6}$.

Another cause is GERD, but its mechanism has not yet been established? The neurologic mechanism (neuromuscular hypotonia and impaired neuromuscular control) is cited as an important cause of laryngomalacia ${ }^{8}$.

A retrospective study performed over a 6 years period, between $1^{\text {st }}$ of January 2007 and $31^{\text {st }}$ of December 2012, on 324 patients diagnosed with laryngomalacia, showed that the median age of patients at diagnosis was 3 months and the big majority of the patients $(82.7 \%)$ were full-term newborns 9 . The main presenting symptom was stridor $(92.9 \%)^{9}$. Most patients were also diagnosed with GERD $(69,8 \%)$, and dysphagia occurred in $50.3 \%$ of the patients 9 .

\section{Methods of inVestigating LaRYNGomalacia}

It is important to use a detailed history and physical examination in determining a proper diagnosis. A detailed history is very important in establishing the correct diagnosis and is usually the main factor that leads to laryngomalacia suspicion. At admission, the newborn should be investigated clinically and paraclinically:

- Body temperature.

- Heart rate, heart sounds, oxygen saturation and blood pressure.

- Lengths, head circumference and thorax circumference.

- Respiratory rate, any physical signs of stridor, such as intercostal, suprasternal, supraclavicular retractions.

- Chest X-ray - can identify a diaphragmatic paralysis, congenital pulmonary malformations, pneumothorax, and mediastinal masses for the differential diagnosis with stridor.

- Laboratory testing - for metabolic disorders or sepsis. Hypoglycemia, hypomagnesaemia may lead to an impaired oxygen transportation to the peripheral tissues. Hypomagnesemia may lead to hypotonia, depressed respiratory drive, and apnea.

- Echocardiography - most congenital heart diseases present with cyanosis, tachypnea, or respiratory distress from cardiac failure.

- Routine ultrasound of the brain.

- Electroencephalogram.

- Flexible endoscopy - it is typically used for diagnosing laryngomalacia. It provides a dynamic, real-time visualization of the upper airway, and it can show the collapse of the supraglottic structures during inspiration, leading to inspiratory stridor and airway obstruction. Other findings can be inspiratory prolapse of the arytenoid cartilage, shortened aryepiglottic folds or an omega shaped epiglottis ${ }^{10}$.

- If GERD is associated, the swallowing function should be assessed by a speech pathologist and the objective methods include modified barium swallow studies and fiberoptic endoscopic evaluation of swallowing ${ }^{11}$. 


\section{TREATMENT OF LARYNGOMALACIA}

An estimated $40 \%$ of the infants presenting with laryngomalacia have mild symptoms and another $40 \%$ have moderate symptoms. They can be treated conservatively and the symptoms usually resolve spontaneously by the age of $12-24$ months $^{2}$.

Up to $20 \%$ of the patients present with severe laryngomalacia, that is not likely to cure spontaneously and needs surgical treatment ${ }^{12}$. The most common surgical method used is supraglottoplasty, a method that is still very controversial, because of the possible complications, meaning the impairment of various supraglottic structures during surgery. Supraglottoplasty is performed by resecting the supra-arytenoidal redundant mucosa, incision of shortened aryepiglottic folds, epiglottopexy or a combination of these. Epiglottopexy means de-epithelialization of the vallecula and suture of the lingual side of the epiglottis to the base of the tongue. Indications for supraglottoplasty are severe clinical presentation or insufficient spontaneous resolving of symptoms during the "wait-and-see" policy.

The most common findings are: inward collapse of arytenoids cartilages (type 1), medial displacement of aryepiglottic folds (type 2) and posterocaudal displacement of epiglottis against the posterior pharyngeal wall (type 3).

The type of laryngomalacia determinates the type of supraglottoplasty. Type 1 laryngomalacia necessitates removing redundant supra-arytenoid tissue, type 2 - incision of the shortened aryepiglottic

folds, and type 3 - epiglottopexy. These surgical interventions can be combined ${ }^{13}$.

With the advancements in fiberoptic technology, transoral supraglottoplasty gained widespread acceptance and can now be performed using microlaryngeal instruments, a microdebrider, a $\mathrm{CO} 2$ laser, a thulium laser, and a diode laser. Nevertheless, no differences in terms of the results obtained with these various techniques have been reported in the literature ${ }^{14}$.

In the last decade, the technique of bipolar radiofrequency plasma ablation (RFA) has been well developed and widely accepted in clinical practice. Coblation is currently being widely used in pediatric ear, nose, and throat (ENT) surgery and is reported to be effective, minimally invasive, and economical, but few studies have focused on the use of coblation in managing laryngomalacia ${ }^{15}$.

\section{Conclusions}

Laryngomalacia is the most common cause of stridor in neonates and infants, with a reported incidence of over $60 \%$, and $10 \%$ to $20 \%$ of children with laryngomalacia require further intervention ${ }^{1}$.
Infants with laryngomalacia usually associate swallowing dysfunction and it is important to assess this function before and after treatment. Feeding problems in a new born can lead to dehydration and low weight gain, leading to more severe health problems.

Laryngomalacia is a benign and self-limiting disease. Conservative approaches and close follow-up are adequate in most patients. In severe cases, supraglottoplasty shortens the length of symptomatic disease, compared to "wait-and-see" policy. Neurologic impairment is thought to influence laryngomalacia's severity and outcome. Comorbidities are found to have an influence on the duration and severity of laryngomalacia.

Since the first supraglottoplasty was described by Lane et al in 1984, endoscopic supraglottoplasty with various kinds of instruments has become an effective treatment for this condition ${ }^{16}$.

\section{Compliance with Ethics Requirements:}

"The authors declare no conflict of interest regarding this article"

$$
\text { "No funding for this study" }
$$

\section{References}

1. Holinger P, Johnson KC, Schiller F. Congenital anomalies of the larynx. Ann Otol Rhinol Laryngol 1954; 3:581-606.

2. Thompson DM. Larygnomalacia: factors that influence disease severity and outcomes of management. Curr Opin Otolaryngol Head Neck Surg 2010;18:564-570.

3. Thompson DM. Abnormal sensorimotor integrative function of the larynx in congenital laryngomalacia: A new theory of etiology. Laryngoscope 2007;117(Suppl. 114):1-33.

4. Giannoni C, Sulek M, Friedman EM, Duncan NO III. Gastroesophageal reflux association with laryngomalacia: a prospective study. Int J Pediatr Otorhinolaryngol 1998;43:1120.

5. Hartl TT, Chadha NK. A systematic review of laryngomalacia and acid reflux. Otolaryngol Head Neck Surg 2012;147:619626.

6. Hill FT. Congenital laryngeal stridor. Laryngoscope 1930;40:44-64.

7. Dickson JM, Richter GT, Meinzen-Derr J, et al. Secondary airway lesions in infants with laryngomalacia. Ann Otol Rhinol Laryngol 2009; 118:37-43.

8. Cotton RT, Richardson MA. Congenital laryngeal anomalies. Otolaryngol Clin North Am 1982;14:203-218.

9. Simons JP, Greenberg LL, Mehta DK, et al. Laryngomalacia and swallowing function in children. Laryngoscope 2016;125(2):478-484.

10. Hartnick CJ, Hartley BE, Miller C, Willging JP. Pediatric fiberoptic endoscopic evaluation of swallowing. Ann Otol Rhinol Laryngol 2000; 109:996-999.

11. Willging JP. Endoscopic evaluation of swallowing in children. Int J Pediat Otorhinolaryngol 1995; 32(Suppl):S107S108.28. 
12. Preciado D, Zalzal G. A systematic review of supraglottoplasty outcomes. Arch Otolaryngol Head Neck Surg 2012;138:718721.

13. van der Heijden M, Dikkers FG, Halmos GB. Treatment outcome of supraglottoplasty vs. wait-and-see policy in patients with laryngomalacia. Eur Arch Otorhinolaryngol 2016;273:1507-1513

14. Schroeder J Jr, Bhandarkar ND, Holinger LD. Synchronous airway lesions and outcomes in infants with severe laryngomalacia requiring supraglottoplasty. Arch Otolaryngol Head Neck Surg 2009;135:647-651.

15. Erickson B, Cooper T, El-Hakim H. Factors associated with the morphological type of laryngomalacia and prognostic value for surgical outcomes. JAMA Otolaryngol Head Neck Surg 2014;40:927-933.

16. Lane RW, Weider DJ, Steinem C, et al. Laryngomalacia. A review and case report of surgical treatment with resolution of pectus excavatum. Arch Otolaryngol 1984;110:546-51. 